OPEN ACCESS

Edited by:

Teun J. De Vries,

VU University Amsterdam,

Netherlands

Reviewed by:

Maria Helena Fernandes,

Universidade do Porto, Portugal

Jiankun Xu,

The Chinese University of Hong Kong,

China

Ineke Jansen,

VU University Amsterdam

Netherlands

*Correspondence:

Giacomina Brunetti

giacomina.brunetti@uniba.it

tThese authors have contributed equally to this work

Specialty section:

This article was submitted to

Inflammation,

a section of the journal

Frontiers in Immunology

Received: 13 February 2019 Accepted: 18 April 2019 Published: 03 May 2019

Citation:

Corbo F, Brunetti G, Crupi P, Bortolotti S, Storlino G, Piacente L,

Carocci A, Catalano A, Milani G,

Colaianni G, Colucci S, Grano M, Franchini C, Clodoveo ML, D'Amato G

and Faienza MF (2019) Effects of

Sweet Cherry Polyphenols on

Enhanced Osteoclastogenesis

Associated With Childhood Obesity.

Front. Immunol. 10:1001

doi: 10.3389/fimmu.2019.01001

\section{Effects of Sweet Cherry Polyphenols on Enhanced Osteoclastogenesis Associated With Childhood Obesity}

\author{
Filomena Corbo ${ }^{1 \dagger}$, Giacomina Brunetti ${ }^{2 *}$, Pasquale Crupi ${ }^{3}$, Sara Bortolotti ${ }^{4}$, \\ Giuseppina Storlino ${ }^{4}$, Laura Piacente ${ }^{5}$, Alessia Carocci ${ }^{1}$, Alessia Catalano ${ }^{1}$, \\ Gualtiero Milani ${ }^{1}$, Graziana Colaianni ${ }^{4}$, Silvia Colucci ${ }^{2}$, Maria Grano ${ }^{4}$, Carlo Franchini ${ }^{1}$, \\ Maria Lisa Clodoveo ${ }^{6}$, Gabriele D'Amato ${ }^{7}$ and Maria Felicia Faienza ${ }^{5}$
}

\footnotetext{
${ }^{1}$ Department of Pharmacy-Drug science, University of Bari Aldo Moro, Bari, Italy, ${ }^{2}$ Section of Human Anatomy and Histology, Department of Basic and Medical Sciences, Neurosciences and Sense Organs, University of Bari Aldo Moro, Bari, Italy, ${ }^{3}$ CREA-VE, Council for Agricultural Research and Economics-Research Centre for Viticulture and Enology, Turi, Italy, ${ }^{4}$ Section of Human Anatomy and Histology, Department of Emergency and Organ Transplantation, University of Bari, Bari, Italy, ${ }^{5}$ Paediatric Unit, Department of Biomedical Sciences and Human Oncology, University of Bari Aldo Moro, Bari, Italy, ${ }^{6}$ Interdisciplinary Department of Medicine, University of Bari Aldo Moro, Bari, Italy, ${ }^{7}$ Neonatal Intensive Care Unit, Di Venere Hospital, Bari, Italy
}

Childhood obesity is associated with the development of severe comorbidities, such as diabetes, cardiovascular diseases, and increased risk of osteopenia/osteoporosis and fractures. The status of low-grade inflammation associated to obesity can be reversed through an enhanced physical activity and by consumption of food enrich of anti-inflammatory compounds, such as omega-3 fatty acids and polyphenols. The aim of this study was to deepen the mechanisms of bone impairment in obese children and adolescents through the evaluation of the osteoclastogenic potential of peripheral blood mononuclear cells (PBMCs), and the assessment of the serum levels of RANKL and osteoprotegerin (OPG). Furthermore, we aimed to evaluate the in vitro effects of polyphenol cherry extracts on osteoclastogenesis, as possible dietary treatment to improve bone health in obese subjects. High RANKL levels were measured in obese with respect to controls $(115.48 \pm 35.20 \mathrm{pg} / \mathrm{ml}$ vs. $87.18 \pm$ $17.82 \mathrm{pg} / \mathrm{ml} ; p<0.01)$, while OPG levels were significantly reduced in obese than controls (378.02 $\pm 61.15 \mathrm{pg} / \mathrm{ml}$ vs. $436.75 \pm 95.53 \mathrm{pg} / \mathrm{ml}$, respectively, $p<0.01$ ). Lower Ad-SoS- and BTT Z-scores were measured in obese compared to controls $(p<0.05)$. A significant elevated number of multinucleated $\mathrm{TRAP}^{+}$osteoclasts $(\mathrm{OCs})$ were observed in the un-stimulated cultures of obese subjects compared to the controls. Interestingly, obese subjects displayed a higher percentage of CD14 $/ / C D 16^{+}$ than controls. Furthermore, in the mRNA extracts of obese subjects we detected a 2.5- and 2-fold increase of TNF $\alpha$ and RANKL transcripts compared to controls, respectively. Each extract of sweet cherries determined a dose-dependent reduction in the formation of multinucleated TRAP ${ }^{+}$OCs. Consistently, $24 \mathrm{~h}$ treatment of obese PBMCs with sweet cherry extracts from the three cultivars resulted in a significant reduction of the expression of TNF $\alpha$. In conclusion, the bone impairment in 
obese children and adolescents is sustained by a spontaneous osteoclastogenesis that can be inhibited in vitro by the polyphenol content of sweet cherries. Thus, our study opens future perspectives for the use of sweet cherry extracts, appropriately formulated as nutraceutical food, as preventive in healthy children and therapeutic in obese ones.

Keywords: obesity, inflammation, polyphenols, sweet cherry, osteoclastogenesis, CD14+/CD16+ monocytes, osteoporosis, osteopenia

\section{INTRODUCTION}

Childhood obesity is one of the major health problems in the western world. It is associated with severe co-morbidities including diabetes, cardiovascular diseases $(1,2)$, and bone loss, which can occur early in the life $(3,4)$. It has been reported that the incidence of bone fractures increases in overweight/obese children and adolescents (5). The relationship between childhood obesity and bone impairment has been deepened in animal models. Indeed, Shu et al., found that mice fed with high fat diet (HFD) showed bone loss mainly due to high osteoclastic bone resorption, which is mediated by the increase of proosteoclastogenic cytokines and pre-osteoclasts in the bone marrow microenvironment (6).

Osteoclasts (OCs) derive from monocyte precursors which fuse thank to macrophage colony-stimulating factor (MCSF) and receptor activator of nuclear factor kappa-B ligand (RANKL) and become multinucleated cells able to resorb bone. RANKL is mainly produced by cells of the osteoblastic lineage. However, in inflammation also immune cells represent also an important source of the inflammatory cytokines [revised in Dar et al. (7)]. Recently, it has also been reported that bone marrow adipocytes produce RANKL (8), whose action could be inhibited by Osteoprotegerin (OPG), the soluble decoy receptor of RANKL (7). Other cytokines could also support osteoclastogenesis together with RANKL (9), such as TNF $\alpha$. High levels of this cytokine have been demonstrated in bone diseases as well as in obesity (10-13). This last condition is associated with high levels of pro-inflammatory cytokines, such as interleukins, adipokines, and chemokines, which contribute to the chronic low level of inflammation and oxidative stress which are responsible of the different comorbidities related to obesity $(14,15)$. This status of chronic inflammation can be prevented or even reversed by the loss of body weight through a reduction of food intake and enhanced physical activity (16). It has been reported that physical activity directly or indirectly decreased inflammation (17-19). Moreover, eating foods rich in bioactive anti-inflammatory compounds, such as omega-3 fatty acids (FAs) and polyphenols, has been demonstrated to reduce inflammation $(20,21)$. In particular, the anti-obesity effects of polyphenol-rich diets have been associated to the property of polyphenols to interact with adipose tissues (pre-adipocytes, adipose stem cells, and immune cells).

Sweet cherries are a source of dietary phenolic compounds $(\sim 1,500 \mathrm{mg}$ total phenols per $\mathrm{kg}$ fresh weight), including phenolic acids (hydroxycinnamic acids) and flavonoids (anthocyanins, flavan-3-ols and flavonols), which are known for their health benefits and important role in preventing several chronic diseases related to oxidative stress $(22,23)$. Moreover, they show a low glycemic index respect to other fruits and vegetables and represent a source of vitamins, especially vitamin $\mathrm{C}$ and minerals, such as potassium, phosphorus, calcium, and magnesium $(24,25)$.

Studies in vitro and in vivo have reported that sweet cherries have anti-inflammatory and anti-carcinogenic activity, and characteristics for prevention of cardiovascular disease and diabetes (26).

In the light of these evidences and of the increasing interest on the polyphenol effects on childhood obesity, the aim of this paper were: (a) to deepen the mechanisms of bone impairment in obese children and adolescents, through the evaluation of the serum levels of RANKL and OPG together with the osteoclastogenic potential of peripheral blood mononuclear cells (PBMCs), and (b) to evaluate in vitro, the effects of polyphenols from sweet cherry extracts on osteoclastogenesis, as possible dietary treatment to improve bone health in obesity.

\section{MATERIALS AND METHODS}

\section{Subjects}

Twenty-five obese children with a mean age of $10.8 \pm 2.6$ years were enrolled at Endocrinology Unit of Pediatric Hospital Giovanni XXIII, University A. Moro of Bari. Inclusion criteria were body mass index $(B M I) \geq 95$ th percentile for age and sex. Exclusion criteria were: type 2 diabetes mellitus, secondary or syndromic forms of obesity, hypothyroidism, Cushing disease, viral hepatitis, metabolic or genetic liver diseases, ongoing therapies for chronic systemic diseases. The control group consisted of 21 normal weight healthy children matched for age and gender, recruited on a voluntary basis in the outpatient clinic, who referred to hospital for minor surgery or electrocardiographic record for minor trauma to head, limbs, or chest pain. All the enrolled patients signed an informed consent form. The local ethic committee approved the study. The study was conducted in accordance to the criteria of the declaration of Helsinki. All subjects were in good general health and were not taking drugs in the last 3 months. Serum levels of $(25) \mathrm{OH}-$ vitamin $\mathrm{D}$, osteocalcin, calcium, phosphorus, RANKL, OPG, and alkaline phosphatase were measured as previously reported (10). Bone quality was assessed by QUS measurements, performed with a DBM Sonic 1200 bone profiler (Igea S.r.l., Carpi, MO, Italy) employing a sound frequency of $1.25 \mathrm{MHz}$, as previously described (27). 


\section{Cells and Culture Conditions}

PBMCs were isolated by centrifugation of peripheral blood samples over Histopaque 1077 density gradient (Sigma Chemical, St. Louis, MO), and cultured in $\alpha$-MEM (Life Technologies, Paisley, UK) supplemented with $10 \%$ fetal bovine serum, $100 \mathrm{IU} / \mathrm{ml}$ penicillin, and $100 \mu \mathrm{g} / \mathrm{ml}$ streptomycin (Life Technologies, Inc. Ltd, Uxbridge, UK). To obtain fully differentiated human OCs, the PBMCs were cultured in the presence or absence of $25 \mathrm{ng} / \mathrm{ml}$ recombinant human MCSF and $30 \mathrm{ng} / \mathrm{ml}$ RANKL (R\&D Systems, Minneapolis, MN) for about 20 days. In some experiments, PBMCs were also cultured in the presence of 75 and $100 \mu \mathrm{g} / \mathrm{ml}$ of polyphenol extracts from Giorgia, Bigarreau, and Ferrovia both for mRNA extraction (24 h), MTT assay (24 h) (28), and for osteoclastogenesis (about 20 days) evaluation. The concentrations of the polyphenol extracts were selected according to literature data (29) and calculated according to a previous in vitro study on the effect of quercetin-containing cherry extracts on HepG2 cells (30) by considering 440 dalton as the average molecular weight of the compounds in the extracts; then, they were prepared through vacuum drying of the extracts and re-suspension in a suitable medium for the biological assays. Mature OCs were identified as tartrate-resistant acid phosphatase-positive (TRAP) multinucleated cells (Sigma Aldrich, Milan, Italy) containing three or more nuclei. OC resorbing activity was demonstrated by plating the cells on multiwell slides $\left(4 \times 10^{5}\right.$ cells/well $)$ coated with a calcium phosphate film (Millenium Osteologic; Millenium Biologix Inc, Ontario, Canada). This system incorporates a resorbable artificial bone in the form of submicron calcium phosphate films. The photomicrographs were obtained using a Ellipse E400 microscope (Nikon, Tokyo, Japan) equipped with Nikon Plan Fluor $10 \times / 0.30$ dicl. The microscope was connected with a Nikon digital camera DxM 1200; the acquisition software was Lucia G version 4.61 (build 0.64 ) for Nikon Italy.

\section{Flow Cytometry Analysis}

Fresh peripheral blood samples from patients and controls were stained with PerCp-CD14 and FITC-CD16 antibodies (all Beckmann Coulter, Milan, Italy). Events were acquired using C6 flow cytometer (Becton Dickinson Immunocytometry System, Mountain View, CA, USA). The area of positivity was determined using an isotype-matched $\mathrm{mAb}$, a total of $10^{6}$ events for each sample were acquired.

\section{RNA Isolation and Real Time-PCR Amplification}

Freshly isolated PBMCs of patients and controls, PBMCs treated for $24 \mathrm{~h}$ with polyphenol extracts from sweet cherries as well as OCs cultured in the presence of polyphenol extracts from sweet cherries were subjected to mRNA extraction using spin columns (RNeasy, QIAGEN, Hilden, Germany), and reverse-transcription using iScript Reverse Transcription Supermix (Bio-Rad Laboratories, Hercules, CA). The resulting cDNA was amplified using the SsoFast EvaGreen Supermix (Bio-Rad Laboratories) using the Chromo4 Real-Time PCR Detection System (Bio-Rad Laboratories). The following primer pairs were used for the real-time PCR amplification: RANKL
S: CGTTGGATCACAGCACAT, RANKL AS: GCTCCTCTT GGCCAGTC; TNF $\alpha$ S: ATCTACTCCCAGGTCCTC, TNF $\alpha$ AS: GATGCGGCTGATGGTGT; calcitonin receptor (CalcR) S: AACAATAGAGCCCAAGCCATTTC, CalcR AS: CCAGCA CAGCCATCCATCC; Cathepsin K (Cath K) S: GGCTCAAGG TTCTGCTAC, Cath K AS: GCTTCCTGTGGGTCTTCTTCC; RANK S: CAGGATGCTCTCATTGGTCAG, RANK AS: AGA AAGGAGGTGTGGATTGC; GAPDH S: TCATCCCTGCCT CTACTG; AS: TGCTTCACCACCTTCTTG.

\section{Reagents and Standards for Chemical Procedures}

Formic acid, LC-MS grade water and acetonitrile were purchased from J.T. Baker (Deventer, Holland). Furulic acid, cyanidin-3-O-glucoside chloride, cyanidin-3-O-rutinoside chloride, delphinidin-3-O-glucoside chloride, quercetin-3-Orutinoside, quercetin-3-O-glucoside, kaempferol-3-O-glucoside, kaempferol-3-O-rutinoside, isorhamnetin-3-O-glucoside, $(+)$-catechin, (-)-epicatechin, procyanidins B1 and B2, and epicatechin gallate were purchased from Extrasynthese (Genay, France). Cyanidin-3-O-sophoroside chloride, quercetin-4'-Oglucoside, chlorogenic acid, neochlorogenic acid, and cynarin were purchased from Phytolab (Vestenbergsgreuth, Germany).

\section{Fruit Collection}

Three sweet cherry cultivars (cv. Ferrovia, Bigarreau, and Giorgia) grown in Apulia region (Southern Italy) was used in this study. Samples were harvested at commercial maturity (1st decade of May-2nd decade of June), on the basis of total soluble solids (TSS), measured as ${ }^{\circ}$ Brix using a portable refractometer (Atago PR32, Norfolk, Virginia, USA), and titratable acidity (TA) which was determined in the juice by titration with $0.1 \mathrm{~N}$ of $\mathrm{NaOH}$ (J.T. Baker, Deventer, Holland) to a $\mathrm{pH} 7$ end point (TSS $=\sim 17{ }^{\circ} \mathrm{Brix}$; TA $=\sim 7 \mathrm{~g} / \mathrm{L}$ of citric acid equivalents), in 2014 season using 7 years-old sweet cherry trees located in Turi. The trees were trained to a central leader system and planted at a spacing of $4 \mathrm{~m} \times 4 \mathrm{~m}$ and were grown under usual conditions of irrigation, fertilization, and pest control (31). Five $\mathrm{kg}$ of cherries for each variety were taken on the same day, from four different branches of an individual tree and mixed, then they were frozen in liquid nitrogen and vacuum packed in plastic bags and stored at $-80^{\circ} \mathrm{C}$ for further analysis.

\section{Extraction of Polyphenols From Sweet Cherry and HPLC-MS/MS Analysis}

Polyphenols were extracted from cherries and analyzed through a capillary HPLC 1100 coupled with a triple quadrupole QQQ mass detector (Agilent Technologies Palo Alto, CA, U.S.A.), following the procedure proposed in our previous researches $(31,32)$.

Roughly $100 \mathrm{~g}$ of partially defrosted sweet cherry sample were pitted and a homogenate was obtained using an IKA A11-basic homogenizer (IKA-WERKE GMBH \& CO.KG-Germany). To avoid compounds degradation, the homogenization was completed in darkness and the sample was placed on ice during the whole procedure (around $5 \mathrm{~min}$ ). Ten gram of homogenate was put in a glass flask with $10 \mathrm{~mL}$ of $1 \%$ 
hydroxybutyl anisole (BHA) in methanol and $100 \mu \mathrm{L}$ of ferulic acid internal standard solution $(1,000 \mu \mathrm{g} / \mathrm{mL}$ of methanol). Then, the obtained solution was sonicated in an ultrasonic bath of $130 \mathrm{~W}$ and $40 \mathrm{kHz}$ (SONICA $2200 \mathrm{EP}$, SOLTEC, Milano, Italy) for $1 \mathrm{~h}$ at $25^{\circ} \mathrm{C}$ and the liquid phase was separated by filtration under vacuum. The extraction procedure was repeated twice for the solid phase utilizing fresh methanol (10 and $5 \mathrm{~mL}$ for $30 \mathrm{~min}$, respectively). Finally, the pooled extracts were concentrated down to $10 \mathrm{~mL}$ through a rotavapor Buchi$\mathrm{R}-205$ under vacuum at $40^{\circ} \mathrm{C}$, and stored at $-25^{\circ} \mathrm{C}$ until further analysis.

A Zorbax column SC-C18 $(50 \times 2.1 \mathrm{~mm}$ i.d., particle size $1.8 \mu \mathrm{m}$, Agilent Technologies) was used, with the following gradient system: water/formic acid (99:1, v/v) (solvent A) and acetonitrile/formic acid (99:1, v/v) (solvent B), $0.8 \mathrm{~min}, 95 \%$ $\mathrm{A}-5 \% \mathrm{~B} ; 2.1 \mathrm{~min}, 90 \% \mathrm{~A}-10 \% \mathrm{~B} ; 5.6 \mathrm{~min}, 88 \% \mathrm{~A}-12 \% \mathrm{~B}$; $8 \mathrm{~min}, 81 \% \mathrm{~A}-19 \% \mathrm{~B} ; 9.2 \mathrm{~min} 81 \% \mathrm{~A}-12 \% \mathrm{~B} ; 11.2 \mathrm{~min} 5 \%$ A-95\% B; 12.8 min 5\% A-95\%; 13.2 min 95\% A-5\%; stop time $15 \mathrm{~min}$. The column was kept at $60^{\circ} \mathrm{C}$, the flow was maintained at $0.5 \mathrm{~mL} / \mathrm{min}$ and the sample injection was $1.1 \mu \mathrm{L}$. Both positive and negative ESI mode was used for ionization of molecules with capillary voltage at $4,000 \mathrm{~V}$. Nitrogen was used both as drying gas at a flow rate of $8 \mathrm{~L} / \mathrm{min}$ and as nebulizing gas at a pressure of 30 psi. Temperature of drying gas was $350^{\circ} \mathrm{C}$. In the full scan (MS) and product ion (MS/MS) modes, the monitored mass range was from $\mathrm{m} / z$ 100 to 1,200 . Typically, 2 runs were performed during the HPLC-ESI-MS analysis of each sample. First, an MS full-scan acquisition was performed to obtain preliminary information on the predominant $\mathrm{m} / \mathrm{z}$ ratios observed during the elution. An MS/MS full-scan acquisition was then performed: Quadrupole 1 filtered the calculated $\mathrm{m} / z$ of each compound of interest, while Quadrupole 3 scanned for ions produced by nitrogen collision of these ionized compounds in the chosen range at a scan time of $500 \mathrm{~ms} / \mathrm{cycle}$. All data were acquired and processed using Mass Hunter software (version B.01.04; Agilent Technologies). The optimized parameters (fragmentor voltage and collision energy) for each compound together with the mass transitions adopted for multiple reaction monitoring (MRM) are listed in Table 1S (Supporting Information). To gauge linearity, calibration curves with five/seven concentration points for each compound were prepared separately. Calibration was performed by linear regression of peak-area ratios of the polyphenols to the relative internal standard vs. the respective standard concentration.

\section{Statistical Analyses}

Means and standard deviations of the raw data and regression analysis of calibration samples were carried out using STATISTICA 6.0 software package (StatSoft Inc., Tulsa, OK, U.S.A.).

For statistical analyses of clinical data, the Statistical Package for the Social Sciences (SPSS) for Windows, version 22.0 (SPSS Inc., Chicago, IL, USA) was used. Comparison between groups were performed by $T$-test. Correlations were analyzed with Spearman or Pearson correlation test. The limit of statistical significance was set at 0.05 .
TABLE 1 | Characteristics of study population.

\begin{tabular}{|c|c|c|}
\hline & Controls $N=21$ & Obese patients $N=25$ \\
\hline Gender (male/female) & 9/12 & $9 / 16$ \\
\hline Age (yr) & $8.23 \pm 3.19$ & $10.8 \pm 2.6$ \\
\hline Tanner Stage (I, II, III, IV, V) & $6,10,4,1,0$ & $8,11,4,2,0$ \\
\hline Height SDS & $0.36 \pm 1.02$ & $0.23 \pm 1.48$ \\
\hline Weight SDS & $0.43 \pm 0.87$ & $2.22 \pm 0.70^{\star \star}$ \\
\hline BMI-SDS & $0.25 \pm 0.78$ & $2.31 \pm 0.41^{\star \star}$ \\
\hline Waist circumference (cm) & $72.5 \pm 7.2$ & $92.04 \pm 23.08^{\star \star}$ \\
\hline Total cholesterol (mg/dl) & $154.8 \pm 28.32$ & $164 \pm 33.18$ \\
\hline $\mathrm{HDL}(\mathrm{mg} / \mathrm{dl})$ & $55.67 \pm 9.30$ & $49.08 \pm 8.13$ \\
\hline LDL (mg/dl) & $97.10 \pm 21.03$ & $107.54 \pm 37.62$ \\
\hline Triglycerides (mg/dl) & $67.24 \pm 19.16$ & $73.00 \pm 32.74$ \\
\hline Insulin (microU/mL) & $9.78 \pm 4.50$ & $24.60 \pm 12.02^{\star \star}$ \\
\hline Glucose (ml/dl) & $81.16 \pm 7.14$ & $87.22 \pm 11.35$ \\
\hline HOMA-IR & $2.56 \pm 0.40$ & $4.93 \pm 1.91^{\star \star}$ \\
\hline 25-OH Vitamin D (ng/ml) & $38.64 \pm 14.70$ & $29.70 \pm 12.89$ \\
\hline Osteocalcin (ng/ml) & $38.26 \pm 19.22$ & $47.44 \pm 21.02$ \\
\hline PTH (pg/ml) & $43.05 \pm 15.06$ & $44.07 \pm 17.09$ \\
\hline Calcium (mg/dl) & $9.71 \pm 0.40$ & $9.43 \pm 0.41$ \\
\hline Phosphorus (mg/dl) & $4.54 \pm 1.4$ & $4.54 \pm 0.51$ \\
\hline Ad-Sos-Z-score & $0.48 \pm 0.85$ & $-1.05 \pm 1.17^{\star}$ \\
\hline BTT-Z-score & $0.15 \pm 0.72$ & $-0.39 \pm 1.23^{\star}$ \\
\hline RANKL (pg/ml) & $87.18 \pm 17.82$ & $115.48 \pm 35.20 \S$ \\
\hline OPG (pg/ml) & $436.75 \pm 95.53$ & $378.02 \pm 61.15 \S$ \\
\hline
\end{tabular}

SDS, standard deviation score; BMI, body mass index; PTH, parathyroid hormone; Ca, calcium; P, phosphorus; B-ALP, bone alkaline phosphatase; RANKL, receptor activator of nuclear factor kappa-B ligand; OPG, osteoprotegerin. $\$ p<0.01$; ${ }^{*} p<0.05$; ${ }^{* \star} p<0.001$.

\section{RESULTS}

\section{Clinical Characteristics}

The characteristics of the study population were reported in Table 1. Although, in the normal range, lower Ad-SoS- and BTT$Z$-scores were measured in obese patients compared to controls $(P<0.05)$. The serum levels of $25-\mathrm{OH}$ Vitamin $\mathrm{D}$, calcium, phosphorus, and osteocalcin were comparable to those measured in controls. Interestingly, higher RANKL levels were measured in obese patients with respect to the controls $(115.48 \pm 35.20$ $\mathrm{pg} / \mathrm{ml}$ vs. $87.18 \pm 17.82 \mathrm{pg} / \mathrm{ml} ; p<0.01$ ), while OPG levels were significantly reduced in obese patients than in controls $(378.02 \pm 61.15 \mathrm{pg} / \mathrm{ml}$ vs. $436.75 \pm 95.53 \mathrm{pg} / \mathrm{ml}$, respectively, $p<0.01)$. With adjustment for age RANKL levels correlated with waist circumference $(r=0.144 p<0.022)$, and SDS-BMI $(r=0.129 p<0.038)$, whereas OPG levels correlated with waist circumference $(r=-0.348 p<0.0001)$, SDS-BMI $(r=-0.381$ $p<0.0001)$, BTT-Z-score $(r=0.208 p<0.002)$, HOMA-IR $(r=-0.359 p<0.0001)$.

\section{Osteoclastogenesis in Obese Children and Adolescents}

OC formation was evaluated in cultures of PBMCs from obese patients and controls. A significant elevated number of multinucleated $\mathrm{TRAP}^{+}$OCs were counted in the un-stimulated 
cultures of obese patients (Figure 1B) compared to the controls (Figure 1A), as reported in the histogram (Figure 1C). The addition of the pro-osteoclastogenic M-CSF and RANKL in the cultures from patients did not affect the OC number, but they appear larger compared those observed in the un-stimulated cultures (Figure 1E). Indeed, the number of large OCs $(>10$ nuclei) was greater in stimulated compared with un-stimulated cultures from obese patients $(35 \pm 5$ vs. $20 \pm 6, p<0.01)$. Conversely, M-CSF and RANKL are necessary to trigger OC formation in cultures from controls (Figure 1D), as reported in the histogram (Figure 1F).

To investigate the mechanisms of the enhanced osteoclastogenesis in obese we evaluated both the percentage of $\mathrm{CD} 4^{+} / \mathrm{CD} 16^{+}$circulating pre-osteoclasts as well as the levels of the pro-osteoclastogenic cytokines RANKL and TNF $\alpha$ in PBMC extracts. Interestingly, patients displayed a high percentage of $\mathrm{CD}_{14}{ }^{+} / \mathrm{CD}_{16}{ }^{+}$, compared to the controls (Figure 2). Furthermore, in mRNA extracts of obese patients we detected a 2.5- and 2-fold increase of $\mathrm{TNF} \alpha$ and RANKL transcripts compared to controls, respectively (Figure 3).

\section{Effect of Polyphenols From Sweet Cherry on the Spontaneous Osteoclastogenesis of Obese Children and Adolescents}

Interestingly, we also evaluated in vitro the effect of polyphenol cherry extracts on osteoclastogenesis as possible dietary treatment to improve bone health in obesity.

\section{Polyphenols Content in the Cherries Extracts}

Table 1S listed the amount of the main flavonoids (anthocyanins, flavan-3-ols, and flavonols) and chlorogenic acids, which were identified as previously described $(31,32)$, quantified by HPLCMS/MS analyses in the tested cherries extracts. The content of the phenolic compounds appeared slightly lesser in the extract of Giorgia $(1,391 \mathrm{mg} / 100 \mathrm{~g} \mathrm{FW})$ than Bigarreu and Ferrovia (1,820 and $1,768 \mathrm{mg} / 100 \mathrm{~g}$ FW, respectively), even though both the three varieties were principally characterized by anthocyanins, especially cyanidin-3O-rutinoside, accounting for $19-30 \%$ of total polyphenols, and chlorogenic acids (particularly, trans-3-O-coumaroylquinic acid and trans-3-Ocaffeoylquinic acid) ranging between 70 and $80 \%$ of the total polyphenols (Table 1S).

\section{Polyphenols Effect on Osteoclastogenesis of Obese Children and Adolescents}

We investigated the effect of polyphenol extracts from Giorgia, Bigarreau, and Ferrovia on PBMC cultures of patients. We demonstrated that each extract determined a dose-dependent reduction in the formation of multinucleated TRAP $^{+}$OCs (Figures 4A-C). Furthermore, using the highest dose of polyphenol extracts from Giorgia, Bigarreau, and Ferrovia we demonstrated that the treatment also resulted in a significant reduction of resorption activity (Figure 4D), together with a significant reduction of the expression of OC marker genes, such as calcitonin receptor, cathepsin $\mathrm{K}$ and RANK (Figure 4E). Consistently, $24 \mathrm{~h}$ treatment of PBMCs from patients with polyphenol extracts from Giorgia, Bigarreau, and
Ferrovia resulted in a significant reduction of the expression of $\mathrm{TNF} \alpha$ (Figure 5A), whereas RANKL levels were unchanged (Figure 5B). Furthermore, by MTT we demonstrated that polyphenol extracts did not significantly affect cell viability of PBMCs from patients (Figure 6). These results suggested that polyphenols from sweet cherry inhibit osteoclastogenesis through the reduction of pro-osteoclastogenic cytokines, without affecting cell viability.

\section{DISCUSSION}

This study demonstrated that in obese children the reduced bone mineral density (BMD) is associated to the decrease of OPG levels, the increase of RANKL levels, enhanced formation of OCs, of circulating pre-osteoclasts, and pro-osteoclastogenic cytokines. Interestingly, the spontaneous osteoclastogenesis is inhibited in vitro by sweet cherry polyphenol extracts.

Previous studies demonstrated that obese subjects showed significantly lower OPG levels respect to the controls (33-35); however no correlation has been reported between OPG and BMI $(36,37)$. Otherwise, few studies measured higher levels of OPG in obese subjects compared with the controls (38, 39). However, all the previous studies correlated the levels of OPG with the altered HOMA-IR, fasting insulin or glucose. Our study, to our knowledge, is the first demonstrating a direct correlation between OPG levels and BTT-Z score in obese children.

It is known that obesity is associated with bone fragility and the reduced OPG levels could contribute to this status. We also found increased RANKL levels which could explain the bone impairment associated with excess of adipose tissue. Interestingly, we found that RANKL levels positively correlated with waist circumference. The correlation between a central obesity parameter, as the waist circumference, and RANKL levels detected in serum and saliva samples has been previously demonstrated (40). Our data confirmed that visceral fat accumulation represents the main parameter which can predict the entity of bone impairment in obese subjects. These findings also suggest to evaluate bone status in obese subjects with a higher waist circumference than normal values. It is known that RANKL and OPG altered levels have been associated to the altered osteoclastogenesis characterizing bone diseases (41-43). Indeed, it has been demonstrated that anti-RANKL antibody is useful in the treatment of osteoporosis (44). The alterations of OPG and RANKL levels together with the increase of CD14 ${ }^{+} / \mathrm{CD} 16^{+}$ circulating pre-osteoclasts and $\mathrm{TNF} \alpha$ levels are consistent with the spontaneous osteoclastogenesis of our obese patients as well as of other inflammatory diseases associated with bone loss (45). $\mathrm{CD}_{14}{ }^{+} / \mathrm{CD} 16^{+}$cells have been linked with erosive bone diseases, such as psoriatic arthritis and multiple myeloma (46-48). It is known that $\mathrm{CD} 14^{+} / \mathrm{CD} 16^{+}$cells display an enhanced proosteoclastogenic activity $(47,48)$ thus supporting the key role of this cells in the alteration of bone health in obesity. Consistently, rodent models of obesity also demonstrated the increase of OC precursors in the bone marrow (49). Consistently, the ongoing theory sustains that weight gain determines local inflammation 

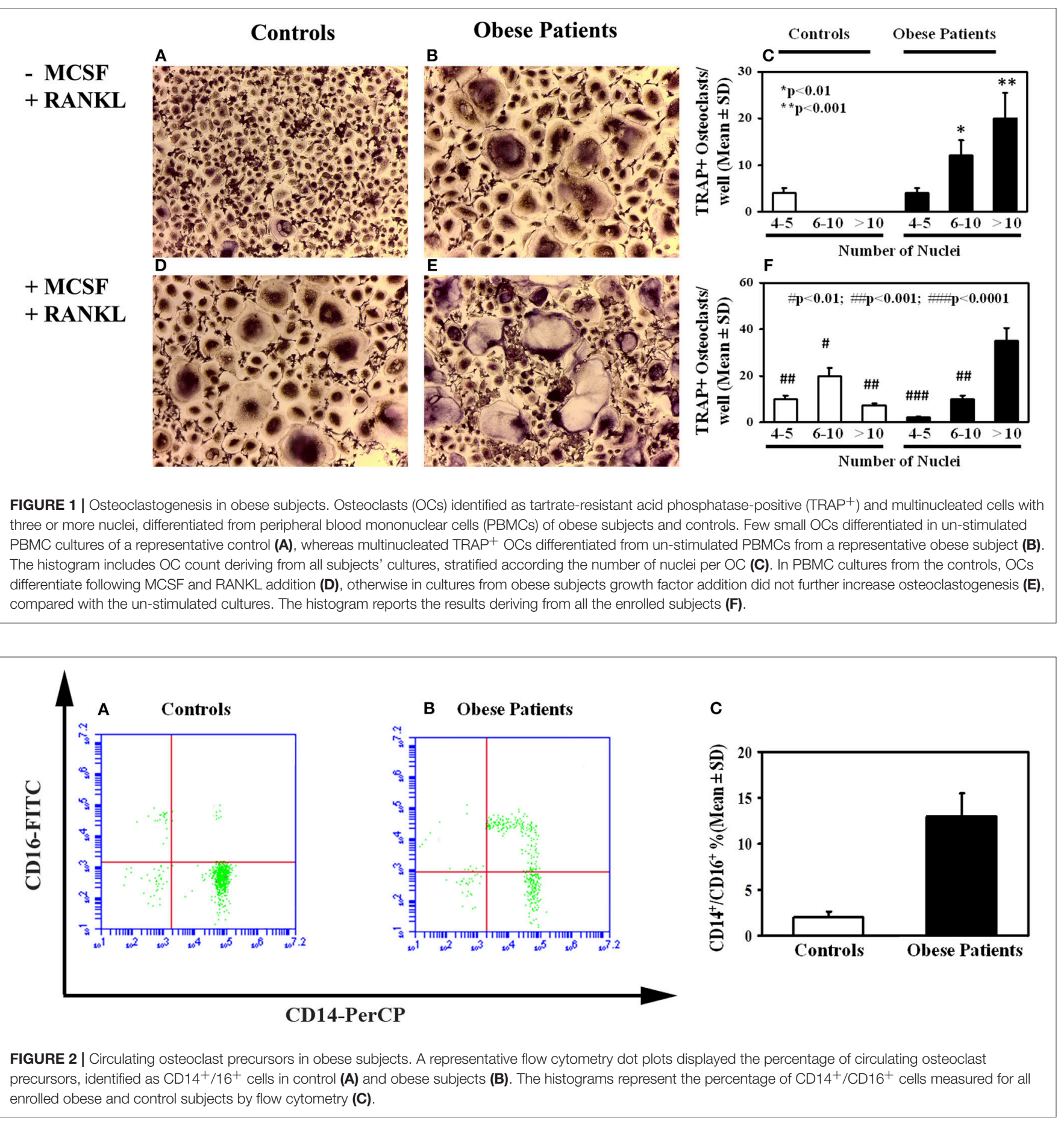

that stimulate the increased recruitment of circulating proinflammatory (Ly6Chi monocytes, also capable of differentiate in OCs in bone. Recruited monocytes differentiate into an M1 macrophage phenotype which is responsible of the chronic inflammation and thus organ damage associated to obesity (15).

An increased mRNA levels of pro-osteoclastogenic molecules such as RANKL and TNFa has been found in young mice fed with HFD (6). Interestingly, our results also displayed high mRNA levels of TNF $\alpha$ and RANKL in PBMCs from obese subjects. It has been reported that childhood obesity is associated to a state of chronic low-grade inflammation as well as numerous inflammation-related molecules such as TNF $\alpha$, interleukin 6 (IL6), and leptin. High levels of these molecules have been linked to co-morbidities associated to obesity (50-53). Furthermore, consisting with our results, transgenic mouse expressing human $\mathrm{TNF} \alpha$ determines the augment of OC precursor percentage (54). 

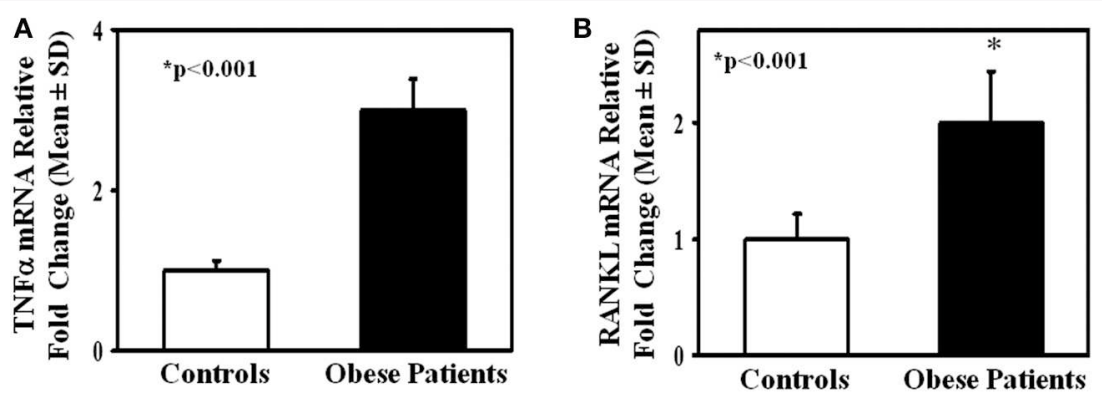

FIGURE 3 | TNF $\alpha$ and RANKL expression in lymphomonocytes from obese subjects. mRNA levels of TNF $\alpha$ (A) and RANKL (B) in lymphomonocytes from all enrolled controls and obese subjects. Obese subjects expressed higher levels of TNF $\alpha$ and RANKL compared to the controls.
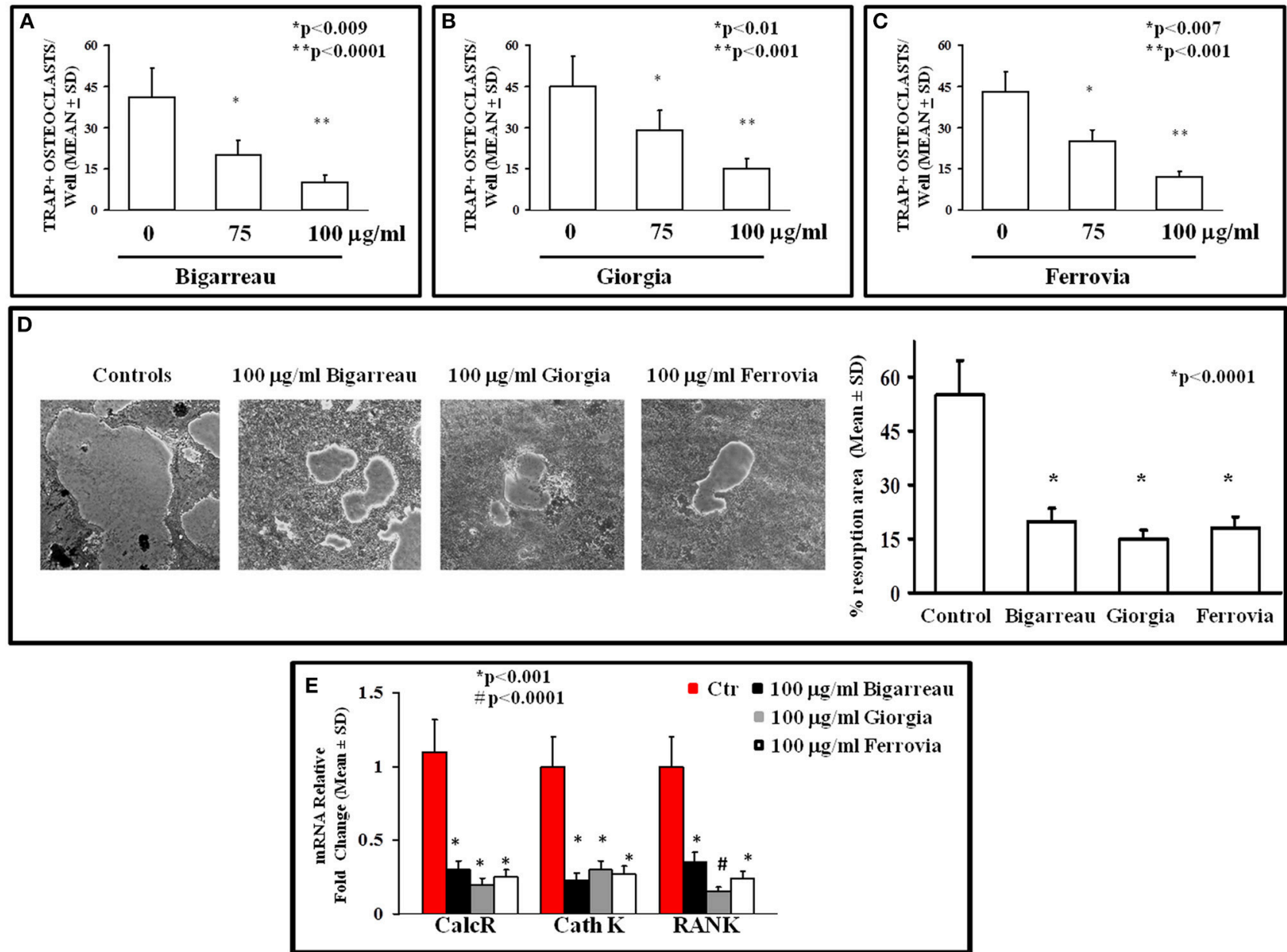

FIGURE 4 | Osteoclastogenesis inhibition by polyphenol extracts from Giorgia, Bigarreau, and Ferrovia. The formation of multinucleated TRAP+ OCs was evaluated in un-stimulated PBMCs from all obese patients cultured in the absence or presence of 75 and $100 \mu \mathrm{g} / \mathrm{ml}$ polyphenol extracts from Bigarreau (A), Giorgia (B), and Ferrovia (C). PBMCs from the patients, cultured on Millenium slides coated with a calcium phosphate film, formed large resorption areas, that were reduced following the treatment with $100 \mu \mathrm{g} / \mathrm{ml}$ polyphenol extracts from Bigarreau, Giorgia, and Ferrovia, as quantified in the histogram (D). The mRNA levels of calcitonin receptor (CalcR), cathepsin K (Cath K), and RANK was evaluated in PBMCs from obese patients cultured in the absence or presence of $100 \mu \mathrm{g} / \mathrm{ml}$ polyphenol extracts from Bigarreau, Giorgia, and Ferrovia (E). 

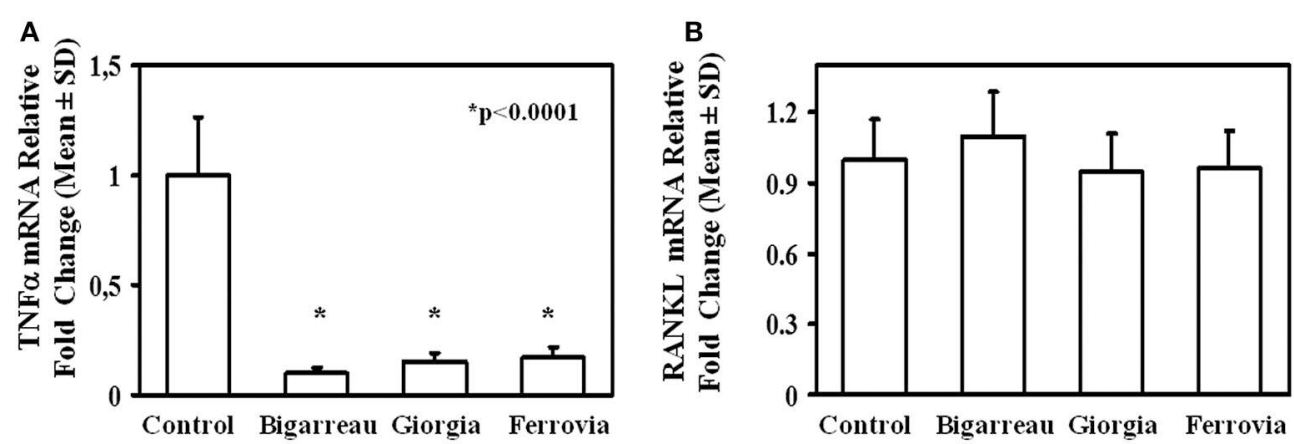

FIGURE 5 | RANKL and TNF $\alpha$ expression in lymphomonocytes from obese subjects. Twenty-four hours treatment of PBMCs from obese subjects with $100 \mu \mathrm{g} / \mathrm{ml}$ polyphenol extracts from Giorgia, Bigarreau, and Ferrovia resulted in a significant reduction of the mRNA levels of TNF $\alpha$ (A), whereas RANKL levels were unchanged (B). The results are referred to all obese subjects.
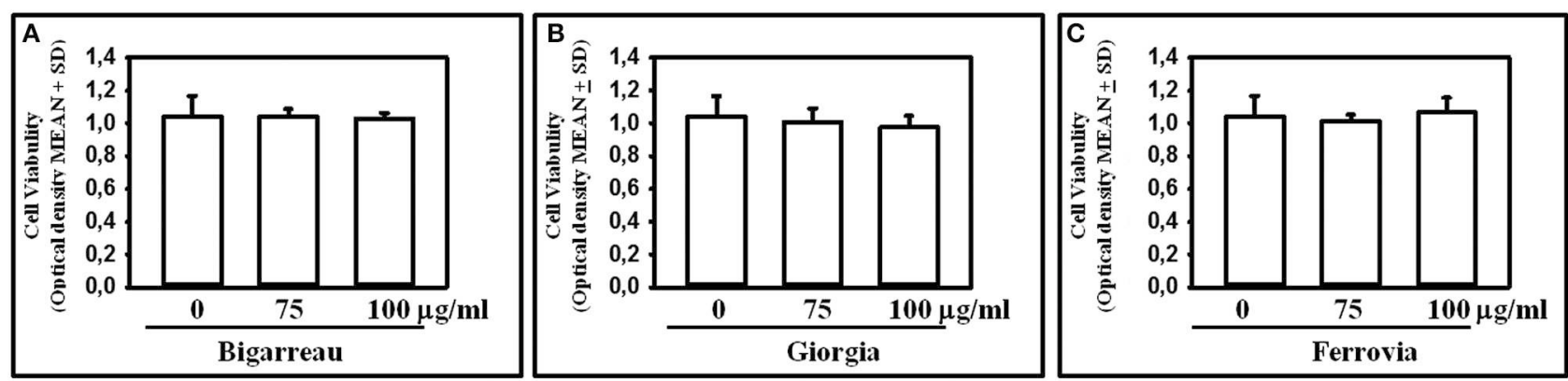

FIGURE 6 | Effect of Polyphenol extracts from Giorgia, Bigarreau, and Ferrovia on PBMC viability. PBMCs were treated for $24 \mathrm{~h}$ with 75 and $100 \mu \mathrm{g} / \mathrm{ml}$ polyphenol extracts from Bigarreau (A), Giorgia (B), and Ferrovia (C) and analyzed by MTT assay to evaluate cell viability. Results are expressed as mean values of optical density at $570 \mathrm{~nm} \pm$ standard deviation (SD).

As countermeasure against chronic low-grade inflammation associated to obesity is represented by dietary advice and nutraceuticals (55). Evidences from in vitro and experimental models suggest the effects of polyphenols on obesity, obesityrelated inflammation, and other metabolic disorders. Their effects include: to induce satiety, to stimulate energy expenditure by inducing thermogenesis in brown adipose tissue, to inhibit adipocyte differentiation and promote adipocyte apoptosis, to modulate lipolysis and activate oxidation (56). Evidence for the effects of polyphenols on obesity and weight control in adult subjects is inconsistent due to the heterogeneity among study populations, intervention period, and polyphenol supplements (57). At the best of our knowledge, there are no studies about the effects of polyphenols extracts on childhood obesity and its comorbidities.

The innovative aspect of this study is related to the inhibition of the spontaneous osteoclastogenesis and reduction of TNF $\alpha$ mRNA levels in PBMC cultures from obese children with the use of polyphenol-rich cherry extracts. This inhibitory effect has been observed with all the three cultivars of sweet cherries, although the content of the phenolic compounds appeared slightly lesser in the extract of Giorgia than Bigarreu and Ferrovia, even though both the three varieties were principally characterized by anthocyanins, especially cyanidin3O-rutinoside, and chlorogenic acids. These polyphenols' compounds play an important role as antioxidants for bone health, both in young people, in order to favor the formation of peak bone mass, and in the elderly and in menopausal women in order to prevent bone loss. Moreover, the use of these antioxidant compounds has been proposed in anti-resorption therapies considering also that they are able to reduce the OC activity without determining their apoptosis, which is useful to restore physiological bone remodeling (58). Consistently, it has been reported that tea and dried plum polyphenols in vitro inhibited osteoclastogenesis $(29,59)$. Of note, it has also been demonstrated the inhibitory effects of sweet cherry anthocyanins on obesity development in HFD fed mice, by slowing down TNF $\alpha$ and IL-6 levels (60). However, this study did not evaluate the effect on bone, which is known to be negatively affected by obesity as well as by HFD. Conversely, Shen et al., reported that in rats green tea polyphenols improved bone health in HFDinduced obesity by the suppression of bone cell activity $(61,62)$. Although the positive effect of green tea administration in obese patients has been evaluated in different studies [revised in Suzuki et al. (63)], there were not published data on bone effects. These literature reports together with our findings let us to speculate 
that also sweet cherry polyphenols can have a protective effect on bone both in HFD fed mice and obese patients.

\section{CONCLUSIONS}

Our study, to our knowledge, is the first demonstrating in obese children a spontaneous osteoclastogenesis inhibited by polyphenols from sweet cherry extracts, through the reduction of $\mathrm{TNF} \alpha$, without affecting cell viability. We also demonstrated that the spontaneous osteoclastogenesis observed in PBMCs from obese children is supported by the high percentage of circulating $\mathrm{CD}_{14}{ }^{+} / \mathrm{CD} 16^{+}$cells and the elevated levels of RANKL and $\mathrm{TNF} \alpha$. Our study opens future perspectives for the use of cherry extracts, appropriately formulated as nutraceuticals as preventive in healthy children and therapeutic in obese ones.

\section{DATA AVAILABILITY}

The datasets generated for this study are available on request to the corresponding author.

\section{ETHICS STATEMENT}

All the enrolled patients signed an informed consent form. The local ethic committee approved the study. The study was conducted in accordance to the criteria of the declaration of Helsinki.

\section{REFERENCES}

1. Faienza MF, Acquafredda A, Tesse R, Luce V, Ventura A, Maggialetti N, et al. Risk factors for subclinical atherosclerosis in diabetic and obese children. Int J Med Sci. (2013) 10:338-43. doi: 10.7150/ijms.5181

2. Styne DM, Arslanian SA, Connor EL, Farooqi IS, Murad MH, Silverstein JH, et al. Pediatric obesity-assessment, treatment, and prevention: an endocrine society clinical practice guideline. J Clin Endocrinol Metab. (2017) 102:709-57. doi: 10.1210/jc.2017-00561

3. Cao JJ. Effects of obesity on bone metabolism. J Orthop Surg Res. (2011) 6:30. doi: 10.1186/1749-799X-6-30

4. Dimitri P. Fat and bone in children - where are we now? Ann Pediatr Endocrinol Metab. (2018) 23:62-9. doi: 10.6065/apem.2018.23.2.62

5. Rana AR, Michalsky MP, Teich S, Groner JI, Caniano DA, Schuster DP. Childhood obesity: a risk factor for injuries observed at a level-1 trauma center. J Pediatr Surg. (2009) 44:1601-5. doi: 10.1016/j.jpedsurg.2008.11.060

6. Shu L, Beier E, Sheu T, Zhang H, Zuscik MJ, Puzas EJ. High-fat diet causes bone loss in young mice by promoting osteoclastogenesis through alteration of the bone marrow environment. Calcif Tissue Int. (2015) 96:31323. doi: 10.1007/s00223-015-9954-Z

7. Dar HY, Azam Z, Anupam R, Mondal RK, Srivastava RK. Osteoimmunology: the Nexus between bone and immune system. Front Biosci. (2018) 23:464-92. doi: $10.2741 / 4600$

8. Fan Y, Hanai JI, Le PT, Bi R, Maridas D, DeMambro V, et al. Parathyroid hormone directs bone marrow mesenchymal cell fate. Cell Metab. (2017) 25:661-72. doi: 10.1016/j.cmet.2017.01.001

9. Lam J, Takeshita S, Barker JE, Kanagawa O, Ross FP, Teitelbaum SL. TNF-alpha induces osteoclastogenesis by direct stimulation of macrophages exposed to permissive levels of RANK ligand. J Clin Invest. (2000) 106:1481-8. doi: 10.1172/JCI11176

10. Brunetti G, Papadia F, Tummolo A, Fischetto R, Nicastro F, Piacente L, et al. Impaired bone remodeling in children with osteogenesis imperfecta treated

\section{AUTHOR CONTRIBUTIONS}

GB, MF, and FC developed the concept and designed the experiments. GC performed most experiments and analyzed data. LP performed cell cultures and ELISA. SB and GS performed flow cytometry. MF and GD provided patients' samples and clinical data. FC, ACi, ACo, GM, MC, PC, and CF developed the chemical part of the paper. GB, MF, FC, and $\mathrm{MC}$ wrote the manuscript and all other authors commented on the manuscript.

\section{FUNDING}

This work was supported by EU through the Regione Puglia: Avviso aiuti a sostegno dei Cluster Tecnologici Regionali per l'Innovazione-Progetto: PERFORM TECH (PUGLIA EMERGING FOOD TECHNOLOGY) - La sicurezza alimentare mediante l'impiego di tecnologie emergenti per l'elaborazione di prodotti funzionali, recupero di sostanze nutraceutiche dai sottoprodotti e valorizzazione energetica degli scarti (grant number LPIJ9P2).

\section{SUPPLEMENTARY MATERIAL}

The Supplementary Material for this article can be found online at: https://www.frontiersin.org/articles/10.3389/fimmu. 2019.01001/full\#supplementary-material

and untreated with bisphosphonates: the role of DKK1, RANKL, and TNF- $\alpha$. Osteoporos Int. (2016) 27:2355-65. doi: 10.1007/s00198-016-3501-2

11. D'Amelio P, Grimaldi A, Pescarmona GP, Tamone C, Roato I, Isaia G. Spontaneous osteoclast formation from peripheral blood mononuclear cells in postmenopausal osteoporosis. FASEB J. (2005) 19:410-2. doi: 10.1096/fj.04-2214fje

12. Ritchlin CT, Haas-Smith SA, Li P, Hicks DG, Schwarz EM. Mechanisms of TNF-alpha- and RANKL-mediated osteoclastogenesis and bone resorption in psoriatic arthritis. J Clin Invest. (2003) 111:821-31. doi: 10.1172/JCI16069

13. Arslan N, Erdur B, Aydin A. Hormones and cytokines in childhood obesity. Indian Pediatr. (2010) 47:829-39. doi: 10.1007/s13312-010-0142-y

14. Faienza MF, Francavilla R, Goffredo R, Ventura A, Marzano F, Panzarino G, et al. Oxidative stress in obesity and metabolic syndrome in children and adolescents. Horm Res Paediatr. (2012) 78:158-64. doi: 10.1159/000342642

15. Kraakman MJ, Murphy AJ, Jandeleit-Dahm K, Kammoun HL. Macrophage polarization in obesity and type 2 diabetes: weighing down our understanding of macrophage function? Front Immunol. (2014) 5:470. doi: 10.3389/fimmu.2014.00470

16. Goran MI, Alderete TL. Targeting adipose tissue inflammation to treat the underlying basis of the metabolic complications of obesity. Nestle Nutr Inst Work Ser. (2012) 73:49-60. doi: 10.1159/000341287

17. Abramson JL, Vaccarino V. Relationship between physical activity and inflammation among apparently healthy middle-aged and older US adults. Arch Intern Med. (2002) 162:1286-92. doi: 10.1001/archinte.162.1 1.1286

18. Geffken DF, Cushman M, Burke GL, Polak JF, Sakkinen PA, Tracy RP. Tracy association between physical activity and markers of inflammation in a healthy elderly population. Am J Epidemiol. (2001) 153:242-50. doi: 10.1093/aje/153.3.242

19. Pischon T, Hankinson SE, Hotamisligil GS, Rifai N, Rimm EB. Leisure-time physical activity and reduced plasma levels of obesity-related inflammatory markers. Obes Res. (2003) 11:1055-64. doi: 10.1038/oby.2003.145 
20. Siriwardhana N, Kalupahana NS, Cekanova M, LeMieux M, Greer B, Moustaid-Moussa N. Modulation of adipose tissue inflammation by bioactive food compounds. J Nutr Biochem. (2013) 24:613-23. doi: 10.1016/j.jnutbio.2012.12.013

21. Kalupahana NS, Claycombe KJ, Moustaid-Moussa N. (n-3) Fatty acids alleviate adipose tissue inflammation and insulin resistance: mechanistic insights. Adv Nutr. (2011) 2:304-16. doi: 10.3945/an.111.000505

22. Picariello G, De Vito V, Ferranti P, Paolucci M, Volpe M. Species- and cultivardependent traits of Prunus avium and Prunus cerasus polyphenols. J Food Comp Anal. (2016) 40:50-7. doi: 10.1016/j.jfca.2015.10.002

23. Girelli CR, De Pascali SA, Del Coco L, Fanizzi FP. Metabolic profile comparison of fruit juice from certified sweet cherry trees (Prunus avium L.) of Ferrovia and Giorgia cultivars: a preliminary study. Food Res Int. (2016) 90:281-7. doi: 10.1016/j.foodres.2016.11.014

24. Yigit D, Baydas E, Güleryüz M. Elemental analysis of various cherry fruits by wavelength dispersive X-ray fluorescence spectrometry. Asian J Chem. (2009) 21:2935-42.

25. Schmitz-Eiberger MA, Blanke MM. Bioactive components in forced sweet cherry fruit (Prunus avium L.), antioxidative capacity and allergenic potential as dependent on cultivation under cover. LWT Food Sci Technol. (2012) 46:388-92. doi: 10.1016/j.lwt.2011.12.015

26. Kelley DS, Adkins Y, Laugero KD. A review of the health benefits of cherries. Nutrients. (2018) 10:E368. doi: 10.3390/nu10030368

27. Faienza MF, Ventura A, Delvecchio M, Fusillo A, Piacente L, Aceto G, et al. High sclerostin and Dickkopf-1 (DKK-1) serum levels in children and adolescents with type 1 diabetes mellitus. J Clin Endocrinol Metab. (2017) 102:1174-81. doi: 10.1210/jc.2016-2371

28. Mori G, Brunetti G, Colucci S, Ciccolella F, Coricciati M, Pignataro P, et al. Alteration of activity and survival of osteoblasts obtained from human periodontitis patients: role of TRAIL. J Biol Regul Homeost Agents. (2007) 21:105-14.

29. Oka Y, Iwai S, Amano H, Irie Y, Yatomi K, Ryu K, et al. Tea polyphenols inhibit rat osteoclast formation and differentiation. J Pharmacol Sci. (2012) 118:55-64. doi: 10.1254/jphs.11082FP

30. Snyder SM, Zhao B, Luo T, Kaiser C, Cavender G, Hamilton-Reeves J, et al. Consumption of quercetin and quercetin-containing apple and cherry extracts affects blood glucose concentration, hepatic metabolism, and gene expression patterns in obese C57BL/6J high fat-fed mice. J Nutr. (2016) 146:1001-7. doi: 10.3945/jn.115.228817

31. Crupi P, Genghi R, Antonacci D. In-time and in-space tandem mass spectrometry to determine the metabolic profiling of flavonoids in a typical sweet cherry (Prunus avium L.) cultivar from Southern Italy. J Mass Spectrom. (2014) 49:1025-34. doi: 10.1002/jms.3423

32. Crupi P, Bleve G, Tufariello M, Corbo F, Clodoveo ML, Tarricone L. Comprehensive identification and quantification of chlorogenic acids in sweet cherry by tandem mass spectrometry techniques. J Food Comp Anal. (2018) 73:103-11. doi: 10.1016/j.jfca.2018.06.013

33. Ugur-Altun B, Altun A, Gerenli M, Tugrul A. The relationship between insulin resistance assessed by HOMA-IR and serum osteoprotegerin levels in obesity. Diabetes Res Clin Pract. (2005) 68:217-22. doi: 10.1016/j.diabres.2004.10.011

34. Holecki M, Zahorska-Markiewicz B, Janowska J, Nieszporek T, WojaczynskaStanek K, Zak-Golab A, et al. The influence of weight loss on serum osteoprotegerin concentration in obese perimenopausal women. Obesity. (2007) 15:1925-9. doi: 10.1038/oby.2007.229

35. Erol M, Bostan Gayret O, Tekin Nacaroglu H, Yigit O, Zengi O, Salih Akkurt $\mathrm{M}$, et al. Association of osteoprotegerin with obesity, insulin resistance and non-alcoholic fatty liver disease in children. Iran Red Crescent Med J. (2016) 18:e41873. doi: 10.5812/ircmj.41873

36. Gannage-Yared MH, Fares F, Semaan M, Khalife S, Jambart S. Circulating osteoprotegerin is correlated with lipid profile, insulin sensitivity, adiponectin and sex steroids in an ageing male population. Clin Endocrinol. (2006) 64:6528. doi: 10.1111/j.1365-2265.2006.02522.x

37. Gannagé-Yared MH, Yaghi C, Habre B, Khalife S, Noun R, Germanos-Haddad $\mathrm{M}$, et al. Osteoprotegerin in relation to body weight, lipid parameters insulin sensitivity, adipocytokines, and C-reactive protein in obese and non-obese young individuals: results from both cross-sectional and interventional study. Eur J Endocrinol. (2008) 158:353-9. doi: 10.1530/EJE-07-0797
38. Kotanidou EP, Kotanidis CP, Giza S, Serbis A, Tsinopoulou VR, Karalazou $\mathrm{P}$, et al. Osteoprotegerin increases parallel to insulin resistance in obese adolescents. Endocr Res. (2018) 44:1-7. doi: 10.1080/07435800.2018.1480630

39. Suliburska J, Bogdanski P, Gajewska E, Kalmus G, Sobieska M, Samborski W. The association of insulin resistance with serum osteoprotegerin in obese adolescents. J Physiol Biochem. (2013) 69:847-53. doi: 10.1007/s13105-013-0261-8

40. Serrano-Piña R, Trujillo-Güiza ML, Scougall Vilchis RJ, Layton-Tovar CF, Mendieta-Zerón H. sRANKL and its correlation with metabolic syndrome parameters in children. Int J Paediatr Dent. (2018) 28:633-40. doi: 10.1111/ipd.12422

41. Ventura A, Brunetti G, Colucci S, Oranger A, Ladisa F, Cavallo L, et al. Glucocorticoid-induced osteoporosis in children with 21-hydroxylase deficiency. Biomed Res Int. (2013) 2013:250462. doi: 10.1155/2013/250462

42. Brunetti G, Marzano F, Colucci S, Ventura A, Cavallo L, Grano M, et al. Genotype-phenotype correlation in juvenile Paget disease: role of molecular alterations of the TNFRSF11B gene. Endocrine. (2012) 42:266-71. doi: 10.1007/s12020-012-9705-0

43. Terpos E, Ntanasis-Stathopoulos I, Gavriatopoulou M, Dimopoulos MA. Pathogenesis of bone disease in multiple myeloma: from bench to bedside. Blood Cancer J. (2018) 8:7. doi: 10.1038/s41408-017-0037-4

44. Faienza MF, Chiarito M, D’Amato G, Colaianni G, Colucci S, Grano M, et al. Monoclonal antibodies for treating osteoporosis. Expert Opin Biol Ther. (2018) 18:149-57. doi: 10.1080/14712598.2018.1401607

45. de Vries TJ, El Bakkali I, Kamradt T, Schett G, Jansen IDC, D’Amelio P. What are the peripheral blood determinants for increased osteoclast formation in the various inflammatory diseases associated with bone loss? Front Immunol. (2019) 10:505. doi: 10.3389/fimmu.2019.00505

46. Wong KL, Yeap WH, Tai JJ, Ong SM, Dang TM, Wong SC. The three human monocyte subsets: implications for health and disease. Immunol Res. (2012) 53:41-57. doi: 10.1007/s12026-012-8297-3

47. Chiu YG, Shao T, Feng C, Mensah KA, Thullen M, Schwarz EM, et al. CD16 (FcRgammaIII) as a potential marker of osteoclast precursors in psoriatic arthritis. Arthritis Res Ther. (2010) 12:R14. doi: 10.1186/ar2915

48. Bolzoni M, Ronchetti D, Storti P, Donofrio G, Marchica V, Costa F, et al IL21R expressing CD14+CD16+ monocytes expand in multiple myeloma patients leading to increased osteoclasts. Haematologica. (2017) 102:773-84. doi: 10.3324/haematol.2016.153841

49. Ootsuka T, Nakanishi A, Tsukamoto I. Increase in osteoclastogenesis in an obese Otsuka Long-Evans Tokushima fatty rat model. Mol Med Rep. (2015) 12:3874-80. doi: $10.3892 / \mathrm{mmr} .2015 .3811$

50. Singer K, Lumeng CN. The initiation of metabolic inflammation in childhood obesity. J Clin Invest. (2017) 127:65-73. doi: 10.1172/JCI88882

51. Martí A, Marcos A, Martínez JA. Obesity and immune function relationships. Obes Rev. (2001) 2:131-40. doi: 10.1046/j.1467-789x.2001.00025.x

52. Dedoussis GV, Kapiri A, Samara A, Dimitriadis D, Lambert D, Pfister M, et al. Expression of inflammatory molecules and associations with BMI in children. Eur J Clin Invest. (2010) 40:388-92. doi: 10.1111/j.1365-2362.2010.02277.x

53. Reinehr T, Stoffel-Wagner B, Roth CL, Andler W. High-sensitive C-reactive protein, tumor necrosis factor alpha, and cardiovascular risk factors before and after weight loss in obese children. Metabolism. (2005) 54:1155-61. doi: 10.1016/j.metabol.2005.03.022

54. Yao Z, Li P, Zhang Q, Schwarz EM, Keng P, Arbini A, et al. Tumor necrosis factor-alpha increases circulating osteoclast precursor numbers by promoting their proliferation and differentiation in the bone marrow through up-regulation of c-Fms expression. J Biol Chem. (2006) 281:11846-55. doi: 10.1074/jbc.M512624200

55. Yarla NS, Polito A, Peluso I. Effects of olive oil on TNF- $\alpha$ and IL-6 in humans: implication in obesity and frailty. Endocr Metab Immune Disord Drug Targets. (2018) 18:63-74. doi: 10.2174/1871530317666171120150329

56. Rupasinghe HPV, Sekhon-Loodu S, Mantso T, Panayiotidis MI. Phytochemicals in regulating fatty acids -oxidation: potential underlying mechanisms and their involvement in obesity and weight loss. Pharmacol Ther. (2016) 165:153-63. doi: 10.1016/j.pharmthera.2016.06.005

57. Castro-Barquero S, Lamuela-Raventós RM, Doménech M, Estruch R. Relationship between mediterranean dietary polyphenol intake and obesity. Nutrients. (2018) 10:1523. doi: 10.3390/nu10101523 
58. Domazetovic V, Marcucci G, Iantomasi T, Brandi ML, Vincenzini MT. Oxidative stress in bone remodeling: role of antioxidants. Clin Cases Miner Bone Metab. (2017) 14:209-16. doi: 10.11138/ccmbm/2017. 14.1.209

59. Bu SY, Lerner M, Stoecker BJ, Boldrin E, Brackett DJ, Lucas EA, et al. Dried plum polyphenols inhibit osteoclastogenesis by downregulating NFATc1 and inflammatory mediators. Calcif Tissue Int. (2008) 82:475-88. doi: 10.1007/s00223-008-9139-0

60. Wu T, Tang Q, Yu Z, Gao Z, Hu H, Chen W, et al. Inhibitory effects of sweet cherry anthocyanins on the obesity development in C57BL/6 mice. Int J Food Sci Nutr. (2014) 65:351-9. doi: 10.3109/096374866.2013.8 54749

61. Shen CL, Chyu MC, Cao JJ, Yeh JK. Green tea polyphenols improve bone microarchitecture in high-fat-diet-induced obese female rats through suppressing bone formation and erosion. J Med Food. (2013) 16:421-7. doi: 10.1089/jmf.2012.0199

62. Shen CL, Han J, Wang S, Chung E, Chyu MC, Cao JJ. Green tea supplementation benefits body composition and improves bone properties in obese female rats fed with high-fat diet and caloric restricted diet. Nutr Res. (2015) 35:1095-105. doi: 10.1016/j.nutres.2015.09.014

63. Suzuki T, Pervin M, Goto S, Isemura M, Nakamura Y. Beneficial effects of tea and the green tea catechin epigallocatechin-3-gallate on obesity. Molecules. (2016) 21:E1305. doi: 10.3390/molecules21101305

Conflict of Interest Statement: The authors declare that the research was conducted in the absence of any commercial or financial relationships that could be construed as a potential conflict of interest.

Copyright (C) 2019 Corbo, Brunetti, Crupi, Bortolotti, Storlino, Piacente, Carocci, Catalano, Milani, Colaianni, Colucci, Grano, Franchini, Clodoveo, D'Amato and Faienza. This is an open-access article distributed under the terms of the Creative Commons Attribution License (CC BY). The use, distribution or reproduction in other forums is permitted, provided the original author(s) and the copyright owner(s) are credited and that the original publication in this journal is cited, in accordance with accepted academic practice. No use, distribution or reproduction is permitted which does not comply with these terms. 